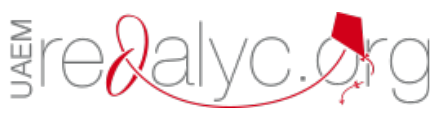

Centro Sur

ISSN: 2600-5743

compasacademico@icloud.com

Grupo Compás

Ecuador

\title{
Políticas públicas, enfoque diferencial y epistemologías decoloniales: una vuelta de tuerca en la reivindicación de derechos de grupos minoritarios
}

Olivar Rojas, Andrés Francisco

Políticas públicas, enfoque diferencial y epistemologías decoloniales: una vuelta de tuerca en la reivindicación de derechos de grupos minoritarios

Centro Sur, vol. 3, núm. 1, 2019

Grupo Compás, Ecuador

Disponible en: http://www.redalyc.org/articulo.oa?id=588861690002

Esta obra está bajo una Licencia Creative Commons Atribución-NoComercial-SinDerivar 4.0 Internacional. 


\title{
Políticas públicas, enfoque diferencial y epistemologías decoloniales: una vuelta de tuerca en la reivindicación de derechos de grupos minoritarios
}

\author{
Public policies, differential approach and decolonial \\ epistemologies: a twist in the claim of minority group rights \\ Andrés Francisco Olivar Rojas aolivar@uniminuto.edu.co \\ Centro Regional Girardot, Colombia \\ http://orcid.org/0000-0003-3504-0347
}

Centro Sur, vol. 3, núm. 1, 2019

Grupo Compás, Ecuador

Recepción: 16 Junio 2018 Aprobación: 12 Abril 2019

Redalyc: http://www.redalyc.org/ articulo.oa?id $=588861690002$
Resumen: El artículo propone un análisis de políticas públicas al margen de los abordajes clásicos, centrados en el impacto o resultados de las políticas, sin tener en cuenta elementos contextuales e ideológicos de la población receptora. En ese sentido, las políticas públicas con enfoque diferencial, dirigidas en Colombia a poblaciones minoritarias víctimas del conflicto armado, deben responder a un proceso de reivindicación de derechos que la democracia liberal no cubre de manera satisfactoria. Por ello, opuesto a la democracia liberal, se propone la democracia radical como estrategia para profundizar la participación ciudadana y, al mismo tiempo, cuestionar las políticas que emanan del Estado y perjudican las comunidades y los territorios. En este punto, las epistemologías decoloniales se entrecruzan con la democracia radical, pues a través del cuestionamiento a decisiones estatales que perjudican a poblaciones destinatarias de las políticas con enfoque diferencial, se proyectan formas diferentes de pensar el desarrollo, cuyo paradigma actual niega la diferencia y excluye proyectos políticos que van en contra del consenso neoliberal-desarrollista.

Palabras clave: democracia liberal, democracia radical, enfoque diferencial, epistemologías decoloniales, políticas públicas.

Abstract: This paper outlines a public policy analysis outside standard approaches, focused on policies' impact or results, without considering contextual and ideological elements on the receiving population. This way, public policies with differential perspective, directed in Colombia at minority population, armed conflict victim, must respond to a right- recognition process, not covered satisfactorily by liberal democracy. Because of this, opossed to liberal democracy, the article proposes radical democracy as an strategy to deepen civic participation and, at the same time, questioning state policies which damages comunities and territories. At this point, decolonial epistemologies intersects with radical democracy, because questioning state policies that damages populations which are differential perspective policies receivers, it's posible to think different development ways, whose current model denies difference and excludes political projects contrary to neoliberal model.

Keywords: Differential Perspective, Decolonial Epistemologies, Liberal Democracy, Public Policies, Radical Democracy.

\section{INTRODUCCIÓN}

Hablar de políticas públicas, en general, implica entender el "Estado en acción" mediante la batería de disposiciones del sistema político para la resolución de problemas públicos. La política, como técnica de organización social destinada al "reparto autoritativo de valores en una 
sociedad” (1992, p. 224), según Easton, ha creado la institución política denominada "Estado" -nacida en el discurso de la Modernidad- con el fin principal de asignar, en instituciones derivadas de él, dos "valores": i) la capacidad o potencia de ejercer la violencia legítima. ii) Conjurar la ley del más fuerte a través del "contrato social".

El ejercicio de la violencia legítima resulta fundamental si se pretende el fin último de la política: preservar el orden y la convivencia entre los seres humanos. La noción de ejercicio de violencia legítima fue teorizada por Max Weber, quien en su célebre "El político y el científico" se encarga de trazar los atributos fundamentales del Estado moderno:

El Estado moderno es una asociación de dominación con carácter institucional que ha tratado, con éxito, de monopolizar dentro de un territorio la violencia física legítima como medio de dominación y que, a este fin, ha reunido todos los medios materiales en manos de sus dirigentes y ha expropiado a todos los funcionarios estamentales que antes disponían de ellos por derecho propio, sustituyéndolos con sus propias jerarquías supremas" (2012, p. 92).

La violencia elimina cualquier asomo de anarquía en los Estados, los cuales, a su vez, se definen como "aquella comunidad humana que, dentro de un determinado territorio (...) reclama (con éxito) para sí el monopolio de la violencia física legítima”. (op.cit, p. 83). Política significará, de este modo, el deseo de participar en el Estado para ejercer el poder, puesto que en él se dan relaciones de dominación sostenidas por la violencia legítima, las cuales determinan la distribución y la conservación de éste.

Aquí es donde se da el punto de encuentro entre la teoría weberiana del Estado como institución en la que se cristaliza la legitimidad política y las diversas teorías contractualistas del Estado, que desde Locke hasta Rousseau, pasando por Hobbes, han entendido la figura del Estado como entidad soberana para garantizar la convivencia. Los hombres entregan su libertad a un ente externo (Estado) y éste a cambio le brinda al cuerpo social la defensa de sus bienes y la preservación de su integridad física.

Cualquier organización política que se llame a sí misma "moderna" debe cumplir con los dos atributos explicados. Colombia, desde su formación como Estado-nación en el siglo XIX, ha mostrado debilidades patentes para monopolizar la violencia legítima y proteger los bienes y la integridad física de sus asociados. Lo cual significa, como corolario, que las políticas públicas en Colombia no cumplen si quiera con los mandatos de la Modernidad política.

La Constitución Política (CP) de 1991, entendida como política pública en su sentido más amplio -un output, o decisión del sistema político, en el sentido eastoniano- amplió el sistema político en tanto se declaró que Colombia es un Estado social de derecho, lo que implica que el Estado debe implementar políticas públicas de manera universal en lo referente no solo a derechos civiles, sino a aquellos referidos al sustento material de la vida humana, como salud, educación, trabajo, vivienda y medio ambiente sano. Así mismo, los diversos mecanismos de participación ciudadana estipulados en la CP buscan 
fomentar la implementación de políticas públicas no solo desde el poder institucionalizado, sino también a través de las decisiones de la ciudadanía.

Ahora, autodenominarse "Estado social de derecho" significa, también, garantizar la protección de derechos de los diversos grupos culturales que habitan la nación colombiana. De manera específica, en relación con la protección de la diversidad cultural, la Constitución Política de 1991, como norma de normas, establece en su Artículo 7 que "El Estado reconoce y protege la diversidad étnica y cultural de la nación colombiana". Por tal motivo, en los últimos 20 años los planes de desarrollo, del nivel nacional, departamental y municipal, adoptaron este acento en la diferencia mediante la aplicación del enfoque diferencial. Esto se puede evidenciar, por ejemplo, en el Plan Nacional de Desarrollo (PND) 2014-2018 (p. 398), según el cual debe realizarse un "acuerdo de consulta previa con grupos étnicos" con el fin de garantizar que las políticas proyectadas por el PND respondan a los criterios de "constitucionalidad, legalidad, pertinencia cultural y correspondencia con las líneas y el planteamiento estratégico del PND”.

Es evidente, en efecto, que estos grupos sociales necesitan de acciones tendientes al restablecimiento de sus derechos de parte del Estado. Dichas acciones son las denominadas políticas públicas con enfoque diferencial, que consisten en la acción del Estado dirigida a atender problemas públicos mediante estrategias enfocadas de manera particular a las características sociales, económicas y culturales de un grupo social, teniendo en cuenta, además, que en el contexto del conflicto armado en Colombia, ha sido el Estado el que ha desprotegido a la población más vulnerable, despojándola de sus derechos esenciales. Igualmente, los grupos al margen de la ley han victimizado a la población civil de manera sistemática, incluso cometiendo contra ella delitos de lesa humanidad. En ese sentido, se ha hecho necesaria la actuación del Estado para restablecer los derechos vulnerados a grupos ciudadanos como indígenas, campesinos, afrodescendientes, mujeres y desplazados, entre otros, mediante acciones de política pública.

El enfoque diferencial, entonces, surge como estrategia de política pública destinada a la protección y reivindicación de derechos de las poblaciones históricamente afectadas por el conflicto armado en Colombia (indígenas, afrodescendientes, mujeres, población LGBTI, entre otras). Así mismo, el Estado colombiano se ha encargado de generar un numeroso conjunto de disposiciones jurídicas (entre ellas, la ley 1448, o Ley de Víctimas y Restitución de Tierras) que pretende ser la herramienta mediante la cual se satisfaga la protección de los derechos vulnerados en el contexto del conflicto armado.

De esta forma nace el enfoque diferencial como estrategia de acción del Estado para atender, de manera diferenciada (es decir, enfocada en las demandas de poblaciones específicas), las necesidades en términos de goce y reivindicación de derechos vulnerados histórica y sistemáticamente a poblaciones determinadas. En Colombia, dichas poblaciones son las víctimas del conflicto armado, indígenas, negritudes, 
raizales, palenqueros, población Rrom, población LGBTI, discapacitados, entre otros. $\mathrm{Al}$ respecto, desde la mencionada ley 1448 se afirma:

"El principio de enfoque diferencial reconoce que hay poblaciones con características particulares en razón de su edad, género, orientación sexual y situación de discapacidad. Por tal razón, las medidas de ayuda humanitaria, atención, asistencia y reparación integral que se establecen en la presente Ley, contarán con dicho enfoque. El Estado ofrecerá\# especiales garantías y medidas de protección a los grupos expuestos a mayor riesgo (...), tales como mujeres, jóvenes, niños y niñas, adultos mayores, personas en situación de discapacidad, campesinos, líderes sociales, miembros de organizaciones sindicales, defensores de derechos humanos y víctimas de desplazamiento forzado".

En ese sentido, es necesario trazar un análisis político que establezca la relación entre las políticas públicas con enfoque diferencial y una efectiva reivindicación de derechos de las poblaciones mencionadas. En esta investigación se parte de la siguiente premisa: la reivindicación de derechos es solo parcialmente posible desde la visión universalista -y a la vez reduccionista- de los derechos, propia de las democracias liberales modernas. Universalista, pues las democracias liberales parten del principio de igualdad jurídica y política de todas las personas; y reduccionista, porque las democracias liberales reducen la categoría "derechos humanos" a los derechos fundamentales.

Por ello, se hace necesario articular al diseño y la implementación de políticas públicas con enfoque diferencial aquello que Chantal Mouffe denomina "democracia radical" (2013, pp. 241-257), entendida como una estrategia para la profundización de la democracia que dé cuenta de las diversas políticas públicas con enfoque diferencial (reflejadas en leyes, decretos, acuerdos, ordenanzas, entre otras disposiciones del sistema político). Dicho análisis político parte de la premisa según la cual las poblaciones objeto de políticas con enfoque diferencial son también aquellas que, desde las epistemologías decoloniales -más adelante se explicará este concepto- reclaman la profundización de la democracia y la ciudadanía, pues han sido asimiladas dentro del concepto universalista de la democracia liberal-representativa.

\section{MATERIALES Y MÉTODOS}

¿Por qué se plantea la distinción entre democracia formal y democracia radical? Diríase que la democracia, como forma de gobierno, posee dos caras que miran hacia direcciones opuestas. Maurice Duverger, en su texto clásico Introducción a la política (1970, pp. 11-17), plantea las dos expresiones de la política, mediante una analogía con el teatro: por un lado, la faz raciniana, envuelta en la pasión, la lucha y la fatalidad. Es la noción realista de los seres humanos como depredadores indomables, a tono con la postura hobbesiana. Por el otro lado, la faz corneliana, relativa al deber, la voluntad y el idealismo de los hombres. La primera entiende la política como un proceso de lucha para evitar la dominación; la segunda es el reino del orden, la justicia, las instituciones y el bien 
común. De esta forma se puede proyectar un paralelo con la disyunción entre democracia formal y democracia radical. La democracia formal se centra en una visión puramente institucional de la democracia. Es decir, se mide la calidad de la democracia desde el respeto por ciertas instituciones que son fundamentales en cualquier democracia moderna: separación de poderes, libertades fundamentales, elecciones periódicas. Se piensa que el cumplimiento de estos requisitos mínimos es suficiente para que una democracia sea plena.

Por otro lado, la democracia radical parte de la base según la cual no basta con la existencia y el funcionamiento de ciertas instituciones. La democracia radical se sustenta en la lucha por profundizar la participación de la ciudadanía en las decisiones y acciones del sistema político, más allá del principio de representación política. En ese sentido, la democracia radical busca modificar las relaciones de poder en una comunidad política, pues las decisiones del pueblo soberano -en este caso, hablando específicamente de las poblaciones objeto de políticas públicas con enfoque diferencial- pudieran ser contrarias al poder institucionalizado. La propuesta de democracia radical entiende lo político como lucha constante por modificar las relaciones de poder.

En ese sentido, el análisis de políticas públicas con enfoque diferencial, desde la democracia radical, se entronca con las epistemologías decoloniales en tanto la colonialidad se entiende como "estructura de dominación y explotación que inicia con el colonialismo" (Curiel, 2007, p. 94). Por ello, la democracia radical, al cuestionar el acento de la democracia liberal en las instituciones y ponerlo en la soberanía popular, cuestiona también la Modernidad no solo como edad histórica, sino como proyecto ideológico surgido en Europa que llevó la tradición occidental a los territorios colonizados. Así, América Latina, como espacio colonizado por la Modernidad, se ha asumido como región atrasada respecto de Europa:

Anibal Quijano define la colonialidad como un patrón mundial de dominación dentro del modelo capitalista, fundado en una clasificación racial y étnica de la población del planeta que opera en distintos ámbitos. Según el autor, la colonialidad es una estructura de dominación y explotación que se inicia con el colonialismo, pero que se extiende hasta hoy día como su secuela. Quijano se centra en varios aspectos fundamentales para explicar las consecuencias de esta estructura de dominación: la racialización de ciertos grupos (africanos e indígenas) que dio lugar a clasificaciones sociales entre superiores/dominantes/ europeos e inferiores/dominados/no europeos; la naturalización del control eurocentrado de territorios y de sus recursos, dando lugar a una colonialidad de articulación política y geográfica; una relación colonial con base en el capital-trabajo que da lugar a clases sociales diferenciadas, racializadas y distribuidas por el planeta (op.cit, p. 94). 


\section{RESULTADOS}

Al hablar de epistemologías decoloniales se enfatiza en la construcción de formas alternativas de construcción del conocimiento. En su sentido más llano, epistemología se refiere a la naturaleza, características y alcances del conocimiento. Nótese, igualmente, que se emplea el concepto en plural epistemologías-, no en singular. El lenguaje siempre refleja las realidades sociales. Por ejemplo, en inglés, conocimiento se escribe "knowledge". Pluralizar la palabra en español no tiene inconveniente; sin embargo, en inglés no se puede decir ni escribir "knowledges" ("conocimientos"), pues es un error gramatical. $\mathrm{Y}$ los errores gramaticales siempre redundan en errores semánticos y pragmáticos.

Así, si en el inglés no puede hablarse de "conocimientos" es porque, en realidad, en Occidente el conocimiento es uno solo: el del paradigma dominante. En América Latina, por el contrario, se habla de tantos conocimientos como filosofías y cosmovisiones existen, por ello se habla de epistemologías decoloniales, o de formas de entender el conocimiento que buscan desmontar el discurso universalizador del desarrollo, montado en el trípode democracia liberal-capitalismo y razón instrumental.

Las epistemologías del sur son epistemologías políticas con una clara intención antihegemónica, en cuanto esta categoría teórica y política busca reivindicar los saberes populares y ancestrales de grupos sociales históricamente marginados por la hegemonía, como indígenas, negritudes, mujeres, comunidad LGBTI, entre otros tipos de nuevas ciudadanías. Este concepto, el de ciudadanía, se resignifica a partir de las epistemologías del sur, en tanto desborda la clásica tripartición propuesta por Thomas Marshall (ciudadanía jurídica, ciudadanía política y ciudadanía social), para pasar a una ciudadanía diferenciada y multicultural, en la que lo múltiple y diverso se convierte en eje transversal de un modelo de desarrollo que le apuesta a construir una democracia participativa (he aquí la ruptura con la democracia representativa liberal) y a visibilizar el conocimiento de quienes han sufrido las imposiciones hegemónicas. Por ejemplo, la resistencia a la minería a cielo abierto y, en general, a la economía extractivista, son muestra de la resistencia de grupos sociales en distintas partes de América Latina que se oponen a una mirada del desarrollo meramente desarrollista, capitalista, neocolonial y explotadora.

\section{DISCUSIÓN}

La propuesta del desarrollo desde las epistemologías del sur no es una cuestión de victimización, sino de resistencia frente a formas hegemónicas de dominación que homogenizan y diluyen la diferencia. Y esta propuesta, valga decir, sí puede enmarcarse dentro de lo que puede llamarse "desarrollo humano", pues implica metodologías dialogantes, en las que se crean nuevos sujetos, sujetos políticos que responden a los problemas sociales de nuestro tiempo, como la justicia ambiental y la lucha contra la hiperindustrialización, que traen como consecuencia el cambio climático 
y la posible desaparición de la especie humana en el mediano plazo, si es que no se actúa de inmediato para detenerlo.

Pasar de la democracia representativa a la democracia participativa y comunitaria, y de la razón instrumental a la razón dialogante, son los desafíos de las sociedades actuales si es que quieren de verdad humanizar el desarrollo. Las epistemologías decoloniales no son una moda académica, sino que encierran una estrategia de política pública eficaz para dotar de legitimidad los sistemas políticos democráticos en América Latina.

\section{Referencias}

Colombia. Congreso de la República (marzo de 2012). Ley 1448 de 2011, Por la cual se dictan medidas de atención, asistencia y reparación integral a las víctimas del conflicto armado interno $y$ se dictan otras disposiciones. Recuperado de http://www.unidadvictimas.gov.co/es/ ley-1448-de-2011/13653

Curiel, O. (2007). Crítica poscolonial desde las prácticas políticas del feminismo antirracista. Nómadas. 26(1), 92-101.

Departamento Nacional de Planeación (2014). Plan Nacional de Desarrollo 2014-2018, Todos por un Nuevo Pais. Recuperado de: https://colaboracion.dnp.gov.co/CDT/PND/PND \%202014-2018\%20Tomo\%201\%20internet.pdf

Duverger, M. (1970). Introducción a la política. Barcelona, España: Ariel

Easton, D. (1992). "Categorías para el análisis sistémico de la política” en Battle, A. (ed.), Diez textos básicos de ciencia política. Barcelona, España: Ariel.

Mouffe, C. (2013). Antagonismo y hegemonía. La democracia radical contra el consenso neoliberal. En Pensar desde la izquierda, mapa del pensamiento critico para un tiempo de crisis, pp. 241-257. Madrid, España: Errata Naturae.

Weber, M. (2012). El politico y el cientifico. Madrid, España: Alianza Editorial. 